\title{
Retrospective comparison of three minimally invasive approaches for adrenal tumors: perioperative outcomes of transperitoneal laparoscopic, retroperitoneal laparoscopic and robot- assisted laparoscopic adrenalectomy
}

Changwei Ji ${ }^{\dagger}$, Qun Lư ${ }^{\dagger}$, Wei Chen, Feifei Zhang, Hao Ji, Shiwei Zhang, Xiaozhi Zhao, Xiaogong Li, Gutian Zhang and Hongqian Guo* (i)

\begin{abstract}
Background: To compare the perioperative outcomes of transperitoneal laparoscopic (TLA), retroperitoneal laparoscopic (RLA), and robot-assisted transperitoneal laparoscopic (RATLA) adrenalectomy for adrenal tumors in our center.

Methods: Between April 2012 and February 2018, 241 minimally invasive adrenalectomies were performed. Cases were categorized based on the minimally invasive adrenalectomy technique. Demographic characteristics, perioperative information and pathological data were retrospectively collected and analyzed.

Results: This study included 37 TLA, 117 RLA, and 87 RATLA procedures. Any two groups had comparable age, ASA score, Charlson Comorbidity Index, and preoperative hemoglobin. The tumor size for RLA patients was $2.7 \pm 1.1 \mathrm{~cm}$, which was significantly smaller compared to patients who underwent TLA/RATLA ( $p=0.000 / 0.000)$. Operative time was similar in any two groups, while estimated blood loss was lower for RATLA group (75.6 $\pm 95.6 \mathrm{ml})$ compared with the TLA group $(131.1 \pm 204.5 \mathrm{ml})(p=0.041)$. Conversion to an open procedure occurred in only one $(2.7 \%)$ patient in the TLA group for significant adhesion and hemorrhage. There were no significant differences between groups in terms of transfusion rate and complication rate. Length of stay was shorter for the RATLA group versus the TLA/RLA group ( $p=0.000 / 0.029)$. In all groups, adrenocortical adenoma and pheochromocytoma were the most frequent histotypes.

(Continued on next page)
\end{abstract}

\footnotetext{
* Correspondence: dr.ghq@nju.edu.cn

${ }^{\dagger}$ Changwei Ji and Qun Lu contributed equally to this work.

Department of Urology, Drum Tower Hospital, Medical School of Nanjing University, Institute of Urology, Nanjing University, 321 Zhongshan Rd,

Nanjing 210008, Jiangsu, People's Republic of China
}

C C The Author(s). 2020 Open Access This article is licensed under a Creative Commons Attribution 4.0 International License, which permits use, sharing, adaptation, distribution and reproduction in any medium or format, as long as you give appropriate credit to the original author(s) and the source, provide a link to the Creative Commons licence, and indicate if changes were made. The images or other third party material in this article are included in the article's Creative Commons licence, unless indicated otherwise in a credit line to the material. If material is not included in the article's Creative Commons licence and your intended use is not permitted by statutory regulation or exceeds the permitted use, you will need to obtain permission directly from the copyright holder. To view a copy of this licence, visit http://creativecommons.org/licenses/by/4.0/ The Creative Commons Public Domain Dedication waiver (http://creativecommons.org/publicdomain/zero/1.0/) applies to the data made available in this article, unless otherwise stated in a credit line to the data. 
(Continued from previous page)

Conclusions: Minimally invasive adrenalectomy is associated with expected excellent outcomes. In our study, the RATLA approach appears to provide the benefits of decreased estimated blood loss and length of stay. Robotic adrenalectomy appears to be a safe and effective alternative to conventional laparoscopic adrenalectomy.

Keywords: Adrenal tumor, Adrenalectomy, Laparoscopy, Robot-assisted surgery, Retroperitoneal

\section{Background}

The incidence of adrenal tumors in the population is approximately 1.5 to $9.0 \%$ [1]. About $10 \%$ of adrenal tumors are functional, and less than $5 \%$ are malignant. Laparoscopic adrenalectomy was first described in 1992 [2]. At present it has routinely replaced the open procedure as the standard treatment for adrenal tumors, with the advantages such as less hemorrhage, shorter hospital stay, and minimally invasive incision [3-5]. Conventional laparoscopic adrenalectomy is generally performed by a transperitoneal laparoscopic (TLA) or retroperitoneal laparoscopic (RLA) approach. TLA is suitable for all sizes of tumors because of the large operating space, while RLA is a more direct approach to the adrenal gland, eliminating the dissection of adjacent structures. Nevertheless, laparoscopy is recognized as associated with a steep and prolonged learning curve for the nonarticulated instruments and inefficient force transmission.

After the application of the da Vinci Surgical System, robotic adrenalectomy has been increasingly performed instead of laparoscopic approach, showing the superior characteristics of magnified three-dimensional imaging and fully articulating instruments $[6,7]$. Moreover, the procedure has been often criticized for the longer operation time and obviously higher cost compared with laparoscopic approach [8].

The aim of the present study was to compare the perioperative outcomes of robot-assisted TLA (RATLA) and conventional laparoscopic adrenalectomy (TLA and RLA) in a high-volume center. The study was presented at the 34th Annual EAU Congress [9].

\section{Methods}

\section{Patients}

This was a retrospective comparative study and consecutive cases of minimally invasive adrenalectomy performed between April 2012 and February 2018 were collected. The operative approaches performed included TLA, RLA, and RATLA. Finally, 241 patients were selected in this study: 37 (15.4\%) patients underwent TLA, 117 (48.5\%) underwent RLA, and 87 (36.1\%) underwent RATLA. All of the operations were performed by one surgeon (Hongqian Guo). The American Society of Anesthesiologists (ASA) and the Charlson Comorbidity Index (CCI) were categorized for all patients according to the grading criteria $[10,11]$. Complications were classified by the modified Clavien-Dindo classification system, which consisted of 5 severity grades [12]. We arranged an endocrinological consultation for each patient preoperatively to identify functional tumors. Patients who had functional adrenal lesions were treated for metabolic abnormalities and hypertension preoperatively. Preoperative imaging examinations included a CT scan or MRI for adrenal.

\section{Surgical technique}

The surgical approach was selected according to the surgeon's preference, physical condition of patient and the features of adrenal tumors. The specific surgical techniques for laparoscopic adrenalectomy and RATLA are described in detail previously [13-15]. The pictures of our robotic surgical team during surgery were presented in Additional file 1. For TLA, the patient was in the lateral position. The ports were routinely inserted at umbilicus and subcostal area in the midclavicular and axillary front lines. For RLA, the first incision was cut below the twelfth rib tip, and the surgeon dissected the retroperitoneal space directly with middle finger. Then, the next two ports were inserted under the direct vision of laparoscopy in midaxillary and axillary front lines. RATLA involved the use of the Si da Vinci robot. The patient was placed in lateral position at about 30 to 60 degrees. There were three robotic trocars, one $12-\mathrm{mm}$ port for the 30-degree downward-angled camera and two 7-mm ports for the da Vinci tools, with monopolar scissors on the right arm and Fenestrated or Maryland grasper on the left arm. The two arms should be kept $8 \mathrm{~cm}$ away from the camera port to avoid obstruction. In addition, if needed, one 12-mm assistance port or one 5 - $\mathrm{mm}$ port to recline the liver were included.

\section{Statistical analysis}

Continuous variables are presented as the mean \pm standard deviation. Student $t$-test (for data with normal distribution) was used to compare continuous variables, and Pearson $x^{2}$ or Fisher exact test was used to compare categorical variables. Univariable and multivariable regressions were used to identify factors predicting estimated blood loss. All reported $p$ values were 2 -sided, and $\mathrm{p}$ value $<0.05$ was considered statistically significant. 
Statistical analysis was performed using SPSS 17.0 (SPSS Inc., Chicago, IL).

\section{Results}

Overall, 37 TLA, 117 RLA, and 87 RATLA patients who underwent procedures were analyzed. Demographic characteristics, perioperative data and pathological results are reported in Table 1 . Any two groups had comparable age, ASA score, Charlson Comorbidity Index, and preoperative hemoglobin. Body mass index (BMI) was high in RLA group compared with the TLA group $(p=0.034)$. The tumor size for RLA patients was $2.7 \pm$ $1.1 \mathrm{~cm}$, which was significantly smaller compared to patients who underwent TLA/RATLA $(p=0.000 / 0.000)$. Of all patients, we found 95 nonfunctional and 146 functional adrenal tumors. Among the functional tumors, there were 58 aldosteronomas, 53 pheochromocytomas, and 35 hypercortisolism.

Operative time was similar in any two groups, while estimated blood loss was lower for RATLA group $(75.6 \pm 95.6 \mathrm{ml})$ compared with the TLA group (131.1 \pm $204.5 \mathrm{ml})(p=0.041)$. Conversion to an open procedure occurred in only one $(2.7 \%)$ patient in the TLA group for significant adhesion and hemorrhage. There were no significant differences between groups in terms of transfusion rate and complication rate. The rate of intraoperative complication was low in all three groups, and most patients who had intraoperative complication developed an episode of hypertension or hemorrhage. The postoperative complication mainly consisted of grade 1 and 2 complications, with only one patient in RLA experiencing grade 3 complication. Length of stay was shorter for the RATLA group compared with the TLA/RLA group ( $p=0.000 / 0.029)$, and shorter for the RLA group compared with the TLA group $(p=0.024)$. The total treatment costs added up to $¥ 27,696$ for TLA, $¥ 27,138$ for RLA and $¥ 68,150$ for RATLA procedures. In all groups, adrenocortical adenoma and pheochromocytoma were the most frequent histotypes. At a median followup of 36 months (range 15-68), no imaging recurrence was observed.

On univariate analysis, the TLA versus RATLA procedure $(p=0.041)$ affected estimated blood loss (Table 2). On multivariate analysis, the tumor size and type of procedure (TLA vs RATLA) were significant predictive factors for estimated blood loss. (Table 3).

\section{Discussion}

Recently laparoscopic adrenalectomy has been the standard surgical procedure for adrenal tumors gradually [16]. Except the acknowledged benefits of laparoscopic surgery, surgeons need to overcome some specific disadvantages, including hand fatigue, the inferior ergonomic instruments, and a two-dimensional surgical view. The robotic system can provide three-dimensional imaging, more precise operation with fewer complications, the elimination of hand tremor, and reduction of surgeon's fatigue, leading to quick recovery of patient while providing feasible oncological and perioperative outcomes [17]. Moreover, robotic adrenalectomy may benefit from a shorter learning curve and intracorporeal sewing compared with laparoscopic approach [18]. In addition, robotic surgery may offer a better selection for obese patients or those with large tumors [19].

In the present study, we compared the perioperative outcomes of three minimally invasive adrenalectomy approaches, including RATLA, TLA, and RLA in a highvolume center. Only a few previous studies exist that compare the results for all these three widely used techniques for minimally invasive adrenalectomy [20, 21]. Although the potential advantages to the surgeon have been shown in robotic adrenalectomy, most studies have demonstrated that the robotic approach has non-inferior oncologic results and perioperative outcomes, when compared with the laparoscopic approach [22]. In the present study, the results suggested that RATLA is as safe and effective as laparoscopic approach, and robotic approach was superior to laparoscopic approach in regard to blood loss and length of hospital stay. Robotic adrenalectomy may also help with partial adrenalectomy by providing clearer visualization and maneuverability to preserving the normal adrenal cortex and venous drainage. Another aspect of disadvantage with robotic approach was the higher cost compared with conventional laparoscopic and open adrenalectomy [8].

Conversion to an open procedure occurred in only 1 patient in the TLA group for significant adhesion and hemorrhage. No Conversion occurred in the RLA/ RATLA group. Regarding the complications, most studies have shown that the risk of perioperative complications in robotic surgery is similar to or lower than that of conventional laparoscopic surgery [6]. In this study, minimally invasive adrenalectomy was performed with excellent perioperative outcomes, regardless of the approach. Most complications were mild, mostly consisted of nausea, pneumonia, hypokalemia, hematoma, and blood transfusion. Only 1 patient in the RLA group experienced grade 3 complication of retroperitoneal hematoma requiring reoperation.

Tumor size in patients undergoing RLA was significantly smaller compared to patients who underwent TLA/RATLA. This difference reflected the influence of selection bias, that is, the patients with smaller tumors were more likely to accept retroperitoneal approach, which may explain the shorter length of stay for the RLA group compared with the TLA group. In any two groups the operative time was similar, while the previous study demonstrated longer operative time in the robotic 
Table 1 Demographic and clinical parameters in the study

\begin{tabular}{|c|c|c|c|c|c|c|}
\hline Parameters & Transperitoneal LA (TLA), $n=37$ & Retroperitoneal LA (RLA), $n=117$ & RATLA, $n=87$ & $p^{a}$ & $p^{b}$ & $p^{c}$ \\
\hline Age, yr, mean (SD) & $47.6 \pm 12.1$ & $49.3 \pm 12.1$ & $48.4 \pm 14.0$ & 0.447 & 0.746 & 0.638 \\
\hline Gender & & & & 0.231 & 0.844 & 0.188 \\
\hline Male & $19(51.4)$ & $47(40.2)$ & $43(49.4)$ & & & \\
\hline Female & 18 (48.6) & $70(59.8)$ & $44(50.6)$ & & & \\
\hline BMI, mean (SD) & $23.6 \pm 2.9$ & $24.9 \pm 3.1$ & $24.7 \pm 3.9$ & 0.030 & 0.081 & 0.809 \\
\hline ASA score $\geq 3$ & $25(67.6)$ & $75(64.1)$ & $62(71.3)$ & 0.700 & 0.681 & 0.281 \\
\hline Charlson Comorbidity Index $\geq 4$ & $6(16.2)$ & $14(12.0)$ & $19(21.8)$ & 0.697 & 0.475 & 0.058 \\
\hline Side & & & & 0.455 & 0.556 & 0.858 \\
\hline Left & $17(45.9)$ & $62(53.0)$ & $45(51.7)$ & & & \\
\hline Right & $20(54.1)$ & $55(47.0)$ & $42(48.3)$ & & & \\
\hline Tumor size, mm, mean (SD) & $5.2 \pm 2.1$ & $2.7 \pm 1.1$ & $4.7 \pm 2.6$ & 0.000 & 0.253 & 0.000 \\
\hline Past abdominal surgery & $5(13.5)$ & $16(13.7)$ & $14(16.1)$ & 0.980 & 0.715 & 0.630 \\
\hline Preop Hb, g/dl, mean (SD) & $130.8 \pm 18.6$ & $133.4 \pm 15.5$ & $135.0 \pm 16.7$ & 0.400 & 0.209 & 0.458 \\
\hline Operative time, min, mean (SD) & $141.6 \pm 47.5$ & $129.8 \pm 38.8$ & $136.1 \pm 41.5$ & 0.130 & 0.521 & 0.268 \\
\hline Estimated blood loss, ml, mean (SD) & $131.1 \pm 204.5$ & $85.4 \pm 88.8$ & $75.6 \pm 95.6$ & 0.194 & 0.041 & 0.452 \\
\hline Open conversion & $1(2.7)$ & $0(0.0)$ & $0(0.0)$ & 0.542 & 0.658 & - \\
\hline Intraoperative transfusions & $2(5.4)$ & $2(1.7)$ & $3(3.4)$ & 0.523 & 0.994 & 0.736 \\
\hline Postoperative transfusions & $3(8.1)$ & $2(1.7)$ & $1(1.1)$ & 0.167 & 0.147 & 1.000 \\
\hline \multicolumn{7}{|l|}{ Complications } \\
\hline Intraoperative & $3(8.1)$ & $5(4.3)$ & $3(3.4)$ & 0.623 & 0.516 & 1.000 \\
\hline Postoperative & $4(10.8)$ & $14(12.0)$ & $6(6.9)$ & 1.000 & 0.710 & 0.229 \\
\hline Clavien 1-2 & $4(10.8)$ & $13(11.1)$ & $6(6.9)$ & & & \\
\hline Clavien 3-4 & $0(0.0)$ & $1(0.9)$ & $0(0.0)$ & & & \\
\hline $\mathrm{Hb}$ at discharge, g/dl, mean (SD) & $116.3 \pm 19.4$ & $121.7 \pm 15.5$ & $121.2 \pm 16.2$ & 0.088 & 0.150 & 0.840 \\
\hline Length of stay, $d$, mean (SD) & $6.6 \pm 2.4$ & $5.0 \pm 3.8$ & $4.1 \pm 1.9$ & 0.024 & 0.000 & 0.029 \\
\hline Readmission & $0(0.0)$ & $2(1.7)$ & $2(2.3)$ & 1.000 & 0.880 & 1.000 \\
\hline Tumor histology & & & & 1.000 & 1.000 & 0.736 \\
\hline Malignant & $1(2.7)$ & $2(1.7)$ & $3(3.4)$ & & & \\
\hline Benign & $36(97.3)$ & $115(98.3)$ & $84(96.6)$ & & & \\
\hline Histology type & & & & 0.307 & 0.664 & 0.588 \\
\hline Adrenocortical adenoma & $16(43.2)$ & $64(54.7)$ & $40(46.0)$ & & & \\
\hline Pheochromocytoma & $6(16.2)$ & $27(23.1)$ & $18(20.7)$ & & & \\
\hline Myelolipoma & $4(10.8)$ & $9(7.7)$ & $13(14.9)$ & & & \\
\hline Adrenocortical carcinoma & $1(2.7)$ & $1(0.7)$ & $1(1.1)$ & & & \\
\hline Metastasis & $0(1.0)$ & $1(0.7)$ & $1(1.1)$ & & & \\
\hline Others & $10(27.0)$ & $15(12.8)$ & $14(16.1)$ & & & \\
\hline
\end{tabular}

Data are $\mathrm{n}(\%)$ unless indicated

a Transperitoneal LA vs Retroperitoneal LA

b Transperitoneal LA vs RATLA

c Retroperitoneal LA vs RATLA

group compared with the laparoscopic group [22]. During follow-up, no imaging recurrence was observed in all patients probably for the benign characteristics of adrenal tumors.

The management of adrenocortical carcinoma is still controversial [23-25]. In this study, adrenocortical carcinoma was resected to clear margins in 2 patients of laparoscopic approach and in 1 patient of robotic approach. Of the 3 patients, one has developed local recurrence at the adrenalectomy bed during follow up.

Most patients with adrenal tumors often showed an abnormal and complex endocrinological presentation. 
Table 2 Univariate analysis of estimated blood loss

\begin{tabular}{lll}
\hline Variable & Estimated blood loss & $p$ Value \\
\hline Age & & 0.602 \\
$\quad \mathbf{5 0}$ & $93.3 \pm 108.7$ & \\
$\quad<\mathbf{5 0}$ & $85.4 \pm 124.5$ & 0.178 \\
Gender & & \\
$\quad$ Male & $100.4 \pm 152.7$ & \\
$\quad$ Female & $80.0 \pm 75.2$ & 0.078 \\
BMI & NA & 0.122 \\
Preop Hb & NA & \\
Surgical procedure & & $\mathbf{0 . 0 4 1}$ \\
$\quad$ TLA vs RATLA & $131.1 \pm 204.5$ vs $75.6 \pm 95.6$ & 0.452 \\
\hline RLA vs RATLA & $85.4 \pm 88.8$ vs 75.6 \pm 95.6 & \\
\hline
\end{tabular}

All patients in our study received a preoperative consultation of endocrinology to determine functional tumors. We always think that an multidisciplinary model of preoperative preparation, operation, and long-term followup is necessary [26], and we strongly suggest a sufficient discussion between urologists and endocrinologists to ensure the patient's safety. Although perioperative blood pressure control and monitoring is strictly enforced, the results show that endocrinological events, such as hypotension and hypokalemia, account for the majority of intraoperative complications.

The limitations of this study include the retrospective nature of the analysis, the selection bias of patients, and the confounding influences of the inherent bias in surgical approach selection. Other important outcomes variables, including patient satisfaction, postoperative pain, and cost, were not evaluated in the current study. Finally, the study lacks a long-term follow-up.

\section{Conclusions}

Our study revealed that robotic adrenalectomy is as safe and effective as laparoscopic approach. The RLA approach appears to provide the benefits of decreased length of stay compared with TLA. The RATLA approach show the benefits of decreased estimated blood loss and length of stay. Robotic adrenalectomy is a safe and effective alternative to conventional laparoscopic approach.

Table 3 Multivariate analysis of estimated blood loss

\begin{tabular}{ll}
\hline Variable & $p$ Value \\
\hline Age & 0.631 \\
BMI & 0.137 \\
Tumor size & $\mathbf{0 . 0 2 2}$ \\
Preop Hb & 0.330 \\
TLA vs RATLA & $\mathbf{0 . 0 3 9}$ \\
RLA vs RATLA & 0.134 \\
\hline
\end{tabular}

\section{Supplementary information}

Supplementary information accompanies this paper at https://doi.org/10. 1186/s12894-020-00637-y.

\section{Additional file 1.}

\section{Abbreviations}

TLA: Transperitoneal laparoscopic adrenalectomy; RLA: Retroperitoneal laparoscopic adrenalectomy; RATLA: Robot-assisted transperitoneal laparoscopic adrenalectomy; ASA: American Society of Anesthesiologists; CCl: Charlson Comorbidity Index; BMI: Body mass index

\section{Acknowledgements}

The abstract was presented at the 34th Annual EAU Congress.

\section{Authors' contributions}

HQG and CWJ: Study design, Manuscript writing. CWJ and QL: Data collection, Data analysis, Manuscript writing. WC, FFZ and HJ: Data collection, Data management, Manuscript editing. SWZ and XZZ: Manuscript editing. XGL and GTZ: Project development, Manuscript writing. All authors read and approved the final manuscript.

\section{Funding}

This study was funded by the National Natural Science Foundation of China (81772710 and 81572519). The funding body did not have any role in the design of the study, the collection, analysis and interpretation of the data or the writing of the manuscript.

\section{Availability of data and materials}

The datasets used and analysed during the current study are available from the corresponding author on reasonable request.

\section{Ethics approval and consent to participate}

This study has been approved by the Ethical Committee of Nanjing Drum Tower Hospital, Medical School of Nanjing University. Written informed consent was obtained from all the patients involved in our study.

\section{Consent for publication}

Not Applicable.

\section{Competing interests}

The authors declare that they have no competing interests.

Received: 26 July 2019 Accepted: 3 June 2020

Published online: 09 June 2020

\section{References}

1. Gopan T, Remer E, Hamrahian AH. Evaluating and managing adrenal incidentalomas [J]. Cleve Clin J Med. 2006:73(6):561-8..

2. Gagner M, Lacroix A, Bolte E. Laparoscopic adrenalectomy in Cushing's syndrome and pheochromocytoma [J]. N Engl J Med. 1992;327(14):1033.

3. Desai MM, Gill IS, Kaouk JH, et al. Robotic-assisted laparoscopic adrenalectomy [J]. Urology. 2002;60(6):1104-7.

4. Chen W, Liang Y, Lin W, et al. Surgical management of large adrenal tumors: impact of different laparoscopic approaches and resection methods on perioperative and long-term outcomes [J]. BMC Urol. 2018;18(1):31.

5. Arslan M, Akin Y, Ates M, et al. Changing surgical approaches for laparoscopic adrenalectomy: single-surgeon data of a 6-year experience [J]. Urol Int. 2013;91(3):304-9.

6. Brandao LF, Autorino R, Laydner $H$, et al. Robotic versus laparoscopic adrenalectomy: a systematic review and meta-analysis [J]. Eur Urol. 2014; 65(6):1154-61.

7. Probst KA, Ohlmann $\mathrm{CH}$, Saar M, et al. Robot-assisted vs open adrenalectomy: evaluation of cost-effectiveness and peri-operative outcome [J]. BJU Int. 2016;118(6):952-7.

8. Morris LF, Perrier ND. Advances in robotic adrenalectomy [J]. Curr Opin Oncol. 2012;24(1):1-6.

9. Ji C, Lu Q, Guo H. Comparison of robot-assisted adrenalectomy with traditional laparoscopic adrenalectomy: perioperative and pathologic outcomes [J]. Eur Urol Supplements. 2019;18(1):e1010. 
10. Mak PH, Campbell RC, Irwin MG, et al. The ASA physical status classification: inter-observer consistency. American Society of Anesthesiologists []]. Anaesth Intensive Care. 2002;30(5):633-40.

11. Charlson M, Szatrowski TP, Peterson J, et al. Validation of a combined comorbidity index [J]. J Clin Epidemiol. 1994;47(11):1245-51.

12. Dindo D, Demartines N, Clavien PA. Classification of surgical complications: a new proposal with evaluation in a cohort of 6336 patients and results of a survey [J]. Ann Surg. 2004;240(2):205-13.

13. Morino M, Beninca G, Giraudo G, et al. Robot-assisted vs laparoscopic adrenalectomy: a prospective randomized controlled trial [J]. Surg Endosc. 2004;18(12):1742-6.

14. Walz MK, Alesina PF, Wenger FA, et al. Posterior retroperitoneoscopic adrenalectomy-results of 560 procedures in 520 patients [J]. Surgery. 2006; 140(6):943-8 discussion 948-50

15. You JY, Lee HY, Son GS, et al. Comparison of robotic adrenalectomy with traditional laparoscopic adrenalectomy with a lateral transperitoneal approach: a single-surgeon experience [J]. Int J Med Robot. 2013;9(3):34550.

16. Brunt LM. SAGES guidelines for minimally invasive treatment of adrenal pathology []]. Surg Endosc. 2013;27(11):3960-80.

17. Taskin HE, Berber E. Robotic Adrenalectomy []]. J Surg Oncol. 2013;19(2): 162-6.

18. Brunaud L, Bresler L, Ayav A, et al. Robotic-assisted adrenalectomy: what advantages compared to lateral transperitoneal laparoscopic adrenalectomy?[J]. Am J Surg. 2008;195(4):433-8.

19. Orhan Agcaoglu MD, Shamil Aliyev MD, Koray Karabulut MD, et al. Robotic versus laparoscopic resection of large adrenal tumors [J]. Ann Surg Oncol. 2012;19(7):2288-94.

20. Lairmore TC, Folek J, Govednik CM, et al. Improving minimally invasive Adrenalectomy: selection of optimal approach and comparison of outcomes [J]. World J Surg. 2016;40(7):1625-31.

21. Chai YJ, Kwon H, Yu HW, et al. Systematic review of surgical approaches for adrenal tumors: lateral Transperitoneal versus posterior retroperitoneal and laparoscopic versus robotic Adrenalectomy []]. Int J Endocrinol. 2014; 2014(10):918346.

22. Karen PS, Heriberto MF, Heslin MJ. Robotic versus laparoscopic adrenalectomy: a comparative study in a high-volume center [J]. Surg Endosc. 2013;27(2):599-602.

23. Miller BS, Ammori JB, Gauger PG, et al. Laparoscopic resection is inappropriate in patients with known or suspected adrenocortical carcinoma [J]. World J Surg. 2010;34(6):1380-5.

24. Porpiglia F, Fiori C, Daffara F, et al. Retrospective evaluation of the outcome of open versus laparoscopic adrenalectomy for stage I and II adrenocortical cancer [J]. Eur Urol. 2010:57(5):873-8.

25. Loncar Z, Djukic V, Zivaljevic V, et al. Survival and prognostic factors for adrenocortical carcinoma: a single institution experience [J]. BMC Urol. 2015; 15:43.

26. Bruno A, Stefanie H, Dirk W, et al. Management of adrenocortical carcinoma [J]. ANZ J Surg. 2010;60(3):273-87.

\section{Publisher's Note}

Springer Nature remains neutral with regard to jurisdictional claims in published maps and institutional affiliations.

Ready to submit your research? Choose BMC and benefit from:

- fast, convenient online submission

- thorough peer review by experienced researchers in your field

- rapid publication on acceptance

- support for research data, including large and complex data types

- gold Open Access which fosters wider collaboration and increased citations

- maximum visibility for your research: over $100 \mathrm{M}$ website views per year

At BMC, research is always in progress.

Learn more biomedcentral.com/submissions 